\title{
Influence of ozone air contamination on the number of deaths ascribed to respiratory causes in Madrid (Spain) during 1990-1998
}

\author{
P. Fernández ${ }^{1}$, R. Herruzo $^{2}$, A. Justel ${ }^{3} \&$ F. Jaque ${ }^{1}$ \\ ${ }^{I}$ Facultad de Ciencias, Universidad Autónoma de Madrid, Spain \\ ${ }^{2}$ Departamento de Medicina Preventiva y Salud Pública, \\ Facultad de Medicina, Madrid, Spain \\ ${ }^{3}$ Departamento de Matemáticas, Universidad Autónoma de Madrid, \\ Madrid, Spain
}

\begin{abstract}
In this paper the influence of the air quality on the mortality associated with respiratory causes in the Madrid (Spain) area during 1990-1998 is analysed. Air pollutants and mortality show that during this period there were two different effects; periodic annual fluctuations plus a monotonic evolution. It has been found that the slope values and signs of the monotonic components are different for each pollutant and mortality ascribed to respiratory causes; negative for particles, $\mathrm{SO}_{2}$, and $\mathrm{NO}_{\mathrm{x}}$ and positive for the $\mathrm{O}_{3}$ concentration and mortality values. A casual relationship between the mortality ascribed to respiratory causes and ozone concentration during the 1900-1998 period has been found. The variation detected in the Ultraviolet Index and traffic in Madrid City during the 1990-1998 period is also considered

Keywords: air pollution, ozone and nitrogen oxides trends, ultraviolet radiation, health effects.
\end{abstract}

\section{Introduction}

In the last years, much effort has been given to the health effects of air contamination, detecting a correlation between air pollution and daily mortality realised in the U.S and Europe (Brimblecombe [1] and Brunekreef and Holgate [2]). A large study concerning the correlation between air pollution and 
mortality was carried out in 20 U.S cities during the 1987-1994 period (Samet et al [3]). In Europe, work in this topic has been developed in the frame of the APHEA project (Air Pollution and Health: an European Approach) (Katsouyami et al [4] and Le Trete et al [5]). It has been recently suggested that small increases in air pollution levels could affect the mortality rate. In particular, an increase in deaths from cardiovascular and respiratory causes has been correlated with enhancement in air contamination (Robert et al [6]). This conjecture is generally accepted, even considering the very low contamination levels of exposure, which are far from being levels that are normally considered unsafe. Among all air pollutants, particles $\left(\mathrm{PM}_{10}\right)$ and sulphur dioxide $\left(\mathrm{SO}_{2}\right)$ have been established as having a strong association with health effects. However, as the concentration of both pollutants in air has decreased strikingly, attention has shifted to ozone $\left(\mathrm{O}_{3}\right)$, nitrous oxides $\left(\mathrm{NO}_{\mathrm{x}}\right)$ and small particles $\mathrm{PM}_{2.5}$. In fact, weak evidence that increases in ozone levels increased the relative rates of deaths during the summer period has been found in some U.S. cities [3].

In this work, a study of air pollution and the mortality rate due to respiratory causes in the area of Madrid (Spain), made over the 1990-1998 period, is presented.

\section{Experimental procedure}

The study was carried out in the area of Madrid (Spain). Its population is 5.423.384, according to the 2001 population census.

The information related to the deaths associated with respiratory causes was supplied by the National Institute of Statistics. Table I shows the codes of the respiratory diseases. Information regarding the daily values of surface air pollutant concentrations was supplied by the Community of Madrid Air Pollution Monitoring Network (MAPMN). The basic parameters, which this network deals, are the following: particles in suspension $\left(\mathrm{PM}_{10}\right), \mathrm{SO}_{2}, \mathrm{NO}_{\mathrm{x}}, \mathrm{CO}$, and $\mathrm{O}_{3}$. The analytical methods are that established within the context of the European Union.

Table 1: $\quad$ Codes of the respiratory diseases.

\begin{tabular}{ll}
\hline Code & \\
\hline \hline J00-J99 & All respiratory causes \\
J10,J11 & Influenza \\
J12-J18 & Pneumonia \\
J40-J44,J45-J47 & Chronic illness and asthma \\
Rest of J00-J99 & Other respiratory causes \\
\hline \hline
\end{tabular}

The concentration values were obtained according to the European norms 85/203/CEE and 92/72/CEE respectively. 
Unfortunately, only the monthly mortality data were available in the 19901998 period. Therefore, from the daily data the monthly concentration values for all pollutants were calculated for their posterior comparison with the mortality data. It is evident that working with monthly means, the effects associated with short term events are minimised and some information could be masked.

The current network has 27 fixed monitoring sets for measuring the levels of air pollutants in the Madrid area.

Transport is considered to be one of the principal sources of pollutant emission, taking into account that there is not a great deal of heavy industry located in the area of Madrid. Madrid parking was supplied by the Traffic Office of Madrid.

The Ultraviolet Index (UVI) data were supplied by the National Institute of Meteorology.

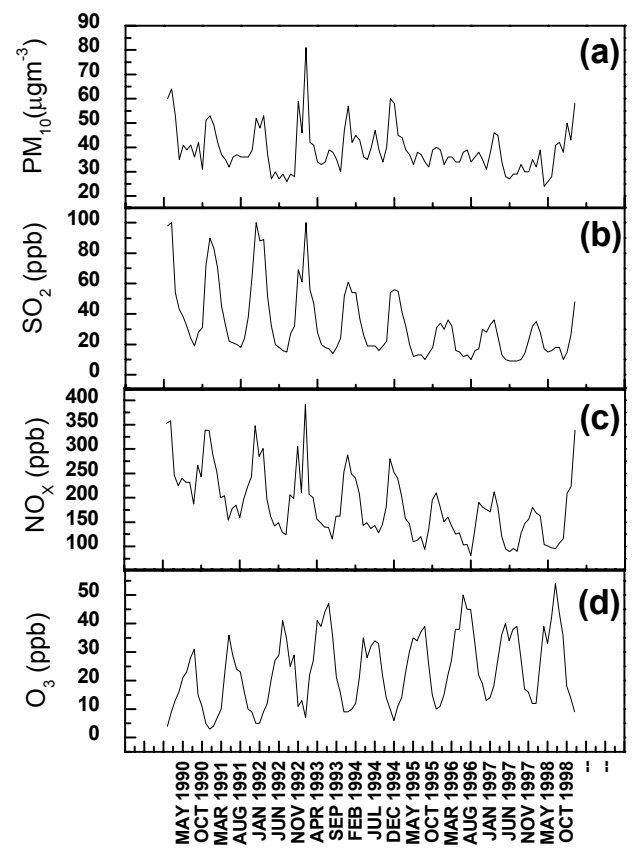

Figure 1: Evolution of the monthly mean concentration values of $\mathrm{PM}_{10}$ (a), $\mathrm{SO}_{2}(\mathrm{~b}), \mathrm{NO}_{\mathrm{x}}(\mathrm{c})$ and $\mathrm{O}_{3}(\mathrm{~d})$.

\section{Results and discussion}

Fig. 1 shows the monthly mean concentration values of $\mathrm{PM}_{10}$ (a), $\mathrm{SO}_{2}$ (b), $\mathrm{NO}_{\mathrm{x}}(\mathrm{c})$ and $\mathrm{O}_{3}(\mathrm{~d})$ during the 1990-1998 period. The experimental data indicate that the tropospheric concentration of $\mathrm{PM}_{10}, \mathrm{SO}_{2}, \mathrm{CO}_{2}$ and $\mathrm{NO}_{\mathrm{x}}$ show, in addition to a periodic annual fluctuations (PAF) with maximum values around the winter session, a monotonic descending component (tend component (TC)). The 
evolution of the $\mathrm{O}_{3}$ content in the air shows in comparison with the former pollutants two different facts; the maximum values are centred on the summertime and the trend component (TC) shows a positive slope.

Fig. 2(a) shows the evolution in the same period of 1990-1998 the number of monthly deaths associated with all respiratory causes (a) and other respiratory causes (b) (see Table 1). As can be seen, together with the PAF effect, a monotonous increase (TC) in the number of deaths is observed. It is important to point out that in the average of the PAF due to respiratory causes, calculated by using the Statistical Analysis Software Program (SPSS), two peaks are perceived; an intense peak in winter and another less intense centred in summertime.

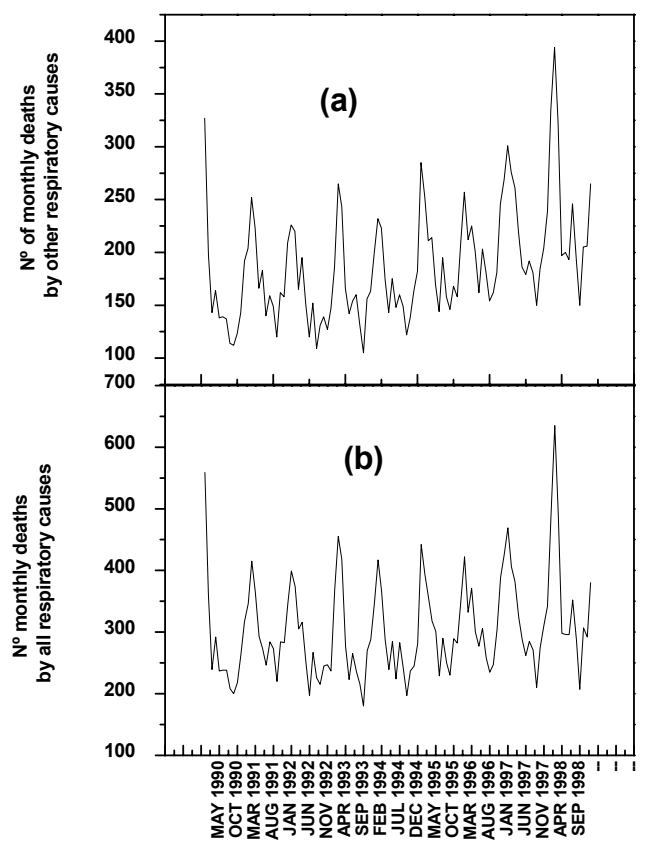

Figure 2: $\quad$ Monthly deaths associated with other respiratory causes (a) and all respiratory causes (b).

Considering these experimental results it is reasonable to split the experimental set data in the PAF and TC components. In addition, as the $\mathrm{O}_{3}$ is the unique pollutant that presents a positive TC slope, the study has been restrict between the mortality associated with respiratory causes and the ozone concentration, taking into account only the trend components.

Fig. 3 shows the TC components obtained using the Statistical Analysis Software Program (SPSS) for the Ozone concentration (a), monthly deaths associated with other respiratory causes (b) and the monthly deaths ascribed to all respiratory causes (c) during the 1990-1998 period. As can be observed the 
monthly mean ozone values fluctuate between $8-35 \mu \mathrm{gm}^{-3}$ and the number of deaths associated with respiratory causes between 200-400 (all respiratory causes) and 120-250 (others causes). It is important to remark that these ozone values are very far below to those considered as potentially hazardous to health. In fact, the "safe" ozone level protection for the population is considered to be

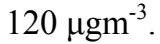

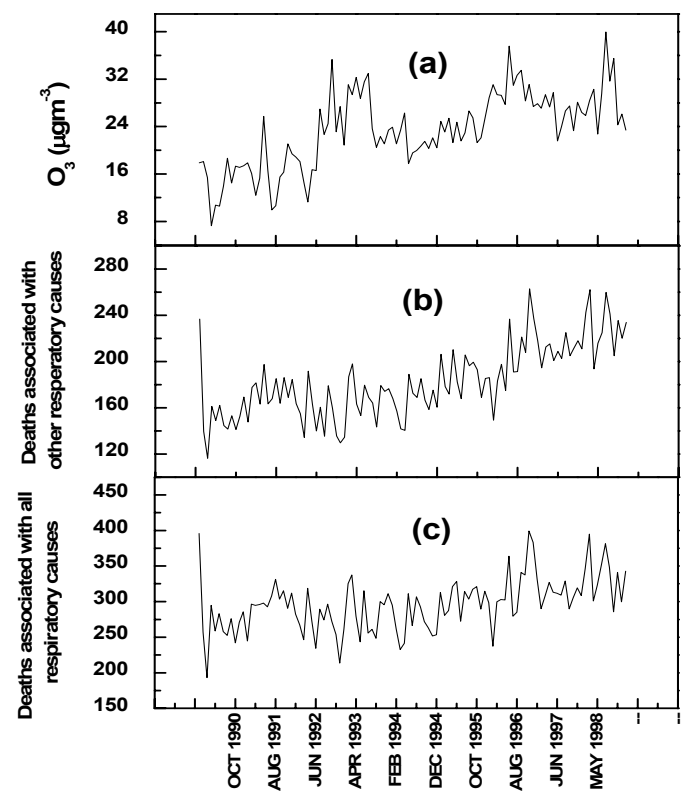

Figure 3: Tends components (TC): (a) ozone concentration (b) and (c) monthly deaths associated with other and all respiratory respectively.

In a first approach, the scatter-plot diagram of ozone concentration versus mortality by all respiratory and other respiratory causes indicates that despite the considerable scatter of the data, there is still a significant correlation with $\mathrm{R}=0.465$ and $\mathrm{p}<0.0001$ between the number of deaths associate with other respiratory causes and the ozone concentration. When all respiratory causes are considered, the correlation is less significant $(\mathrm{R}<0.163, \mathrm{p}<0.19)$. Never the less, it has been found that the monthly rate from other respiratory causes increases by $\sim 11 \%$ respectively for each $10 \mu \mathrm{gr} / \mathrm{m}^{3}$ augmentation of the $\mathrm{O}_{3}$ concentration level. These values are considerably higher than those reported for the U.S cities [3] with the consideration that this value was obtained considering all death causes and not only respiratory causes as in the present work. In an early work (Diaz et al [7]) completed in Madrid City a value of $12 \%$ for an augmentation of $25 \mu \mathrm{gr} / \mathrm{m}^{3}$ has been reported which is in acceptable accordance with the datum calculated in this work. 
The Box-Jenkins metrology has been used for obtaining multivariate, autoregressive integrated moving average (ARIMA) model of the time-based series taken into consideration. Multivariate models show a 8\% (95\% CI: 1.4 to 14.8) increase in mortality for each $10 \mu \mathrm{g} / \mathrm{m}^{3}$ increase in the ozone concentration.

It is generally accepted that the formation of ozone in the troposphere includes a complex series of ultraviolet photolysis reaction involving nitrogen dioxide and hydrocarbons. The major source of anthropogenic emission of $\mathrm{NO}_{\mathrm{x}}$ is the combustion of fossil fuels: heating, power generation and motor vehicles. In particular, in the Madrid area, transport is the basic source of the $\mathrm{NO}_{\mathrm{x}}$ contamination. In this point it is important to remark that in the period 1995-2001 the Madrid parking increased 33\%.

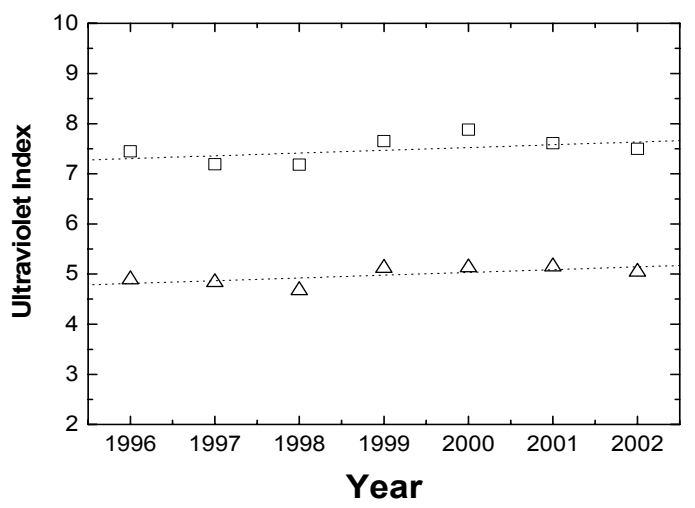

Figure 4: Variation of the Ultraviolet Index during the 1996-2002 period in Madrid.

Fig. 4 shows the variation of the Ultraviolet Index (UVI) (annual and summertime) during the 1996-2002 period, which were the only available data from the National Institute of Meteorology of Madrid. The experimental points correspond to the average of all daily Ultraviolet Index (UVI) maximum for a specific year $(\square)$ or summer season $(\Delta)$. As can be observed, a positive and linear trend with a slope $\sim 7 \%$ is found for both sets of data. This value is in good concordance with the European Environmental Agency [8] that reports an increase of the UV radiation intensity between $7-9 \%$ in the Madrid area during the 1980-1997 period. More explicitly, it has been published an enhancement of the UV radiation intensity in Salonika City (Greece) of 5\% in the 1990-1997 period (Zeferos et al [9]). Therefore, the coincidence of these two phenomena in Madrid City, the increase in the UV radiation level and traffic can explain the rise in ozone concentration.

As has been commented before, a week peak in the number of deaths due to respiratory causes during the summer period was observed, which appears much closer to the maximum value of the $\mathrm{O}_{3}$ concentration. It is clear that the application of time series model covering only the summer months during the 
1990-1998 period is not fully correct. However, a Pearson regression could add light over the Ozone effect in the mortality associated to respiratory causes. Following this argument, fig. 5 shows the Pearson regression between the monthly deaths associated with other respiratory causes and the monthly mean values of the $\mathrm{O}_{3}$ concentration for the summer period. Considering this set of data, a value of $\mathrm{R}=0.729$ is reached, which is significantly higher to that reported in this work when all months are considered. An inspection of fig. 5 reveals that the monthly rate for other respiratory causes increases by a $\sim 17 \%$ for each 10 $\mu \mathrm{gr} / \mathrm{m}^{3}$ augmentation of $\mathrm{O}_{3}$ concentration level. This value is higher than that obtained for the TC in this work when all months are used and considerably higher than that reported for the U.S cities [3] with the consideration that this value was obtained using all death causes and not only respiratory causes, as in the present work.

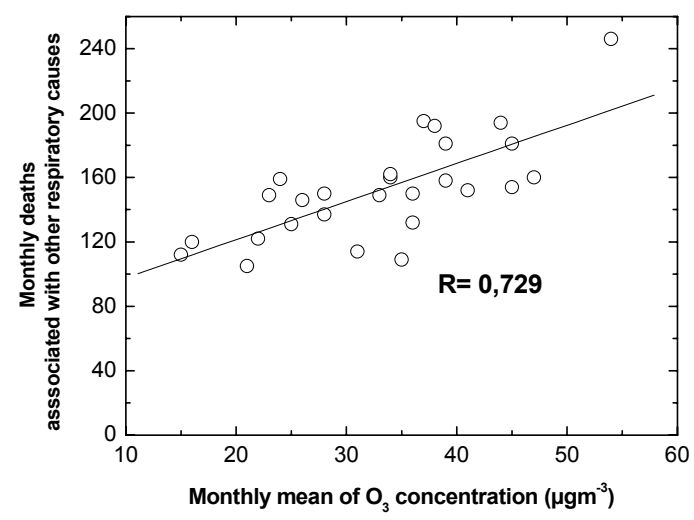

Figure 5: Regression between the monthly deaths associated with other respiratory causes and the monthly mean values of $\mathrm{O}_{3}$ concentration for the summertime.

In summary, this work supports that there is a casual relationship between air pollution associated with the Ozone content and mortality ascribed to respiratory causes associated with the monotonic component (TC) during the 1990-1998 period.

\section{Acknowledgements}

The authors would like to express their gratitude to Professors G. Lifante and P.D. Townsend for helpful discussions and continuous encouragement. F.J. would like to acknowledge the financial support of MAT2005- 05950 project. 


\section{References}

[1] Brimblecombe P (eds). Air pollution and health history. 5-18 Eds Academic Press, San Diego 1990.

[2] Brunekreef. B., Holgate S. T. Air pollution and health (review). Lancet 360, pp. 1233-1242, 2002.

[3] Samet J.M. et al. Fine particulate air pollution and mortality in 20 US cities 1987,1994. N. Engl. J. Med, pp.1742-1749, 2000.

[4] Katsouyami K., Zmirou D., Spix C. Short-term effects of air pollution on health: a European approach using epidemiological time series. Eur. Respir. J. 8, pp. 1030-1038, 1995.

[5] Le Tertre A. et al. Short-term effects of particulate air pollution on cardiovascular diseases in eight European cities. J. Epidemol. Community Health 56, pp.773-779, 2002.

[6] Robert D. et al. Air pollution and cardiovascular disease: a statement for healthcare professional from the Expert Panel On Population and Prevention Science of the Amerial Heart Association. AHA Scientific Statement Circulation. 109, pp. 2655-2671, 2004.

[7] Diaz J. et al. Modelling of air pollution and its relationship with mortality and morbidity in Madrid Spain. Int. Arch. Occup. Environ. Health. 72, pp. 366-376, 1999.

[8] Europe's Environment: The Second Assessment 1998. Elsevier Science Ltd Luxemburg , 1998.

[9] Zeferos C., Meleti C., Balis D., Tourpali K., Bais A. F. Quasil-biennial and longer-term changes in clear sky UV-B solar irradiance. Geophys. Res. Letters. 25, 4345-4348, (1008). 